\title{
Stability of slopes of municipal solid waste landfills with co-disposal of biosolids
}

\author{
M. Chopra, D. Reinhart, M. Vajirkar \& B. Koodhathinkal \\ University of Central Florida, Orlando, Florida, USA
}

\begin{abstract}
This paper deals with the impact of the addition of biosolids on the geotechnical properties of class I landfills with Municipal Solid Waste (MSW). The properties are estimated from a field exploration program using the Cone Penetration Test (CPT). The geotechnical shear strength parameters (angle of internal friction and cohesion) of MSW and biosolids mixture are estimated by correlation with the CPT results. These parameters are then used to study the impact of the addition of biosolids on the stability of the slope of the landfill. The slope stability analysis is conducted on various landfill models using the software SLOPE/W. The waste is assumed to act similar to a cohesionless soil. Based on the field explorations, the angle of internal friction was found to be about $29^{\circ}$. Previous research indicated that the most suitable approach to introducing biosolids into the landfill was in the form of trenches. From the slope stability analysis, it was found that the factor of safety reduces significantly with the introduction of biosolids due to a reduction in the shear strength and with increase in the overall moisture content.
\end{abstract}

Keywords: landfills, biosolids, slope stability analysis, cone penetrometer.

\section{Introduction}

Landfills are well engineered facilities that are used for disposal of Municipal Solid Waste (MSW) and are located, designed, monitored, operated and financed to ensure compliance with federal regulations. Disposal of water treatment facility sludge and wastewater treatment facility biosolids presents significant challenges to facility operators, as this practice often violates loading of metals and exceeds the allowable levels of pathogens for land application. Thus, 
landfilling of the biosolids is promising as it results in minimal contact with humans and can provide moisture in the landfill for it to act as a bioreactor.

With the addition of sludge and biosolids, significant changes in the composition and characteristics of landfill may take place. The stability of waste slopes is particularly important and depends on the strength properties of the MSW with biosolids. The complexity of the problem is further increased by the heterogeneous nature of waste, placement conditions and level of decay of various constituents of the landfills. Proper analysis and design of the landfills have pushed the boundaries of geotechnical engineering practice, in terms of proper identification and assessment of strength and deformation characteristics of waste materials (Sharma et al. [1]; Sadek et al. [2]).

Typical laboratory approaches to measure the geotechnical parameters of the waste such as density, moisture content, cohesion, and shear strength have limitations due the heterogonous nature of the MSW. The scarcity of data is due to the difficulties in sampling and testing the refuse. This difficulty is further compounded by the fact that refuse composition and properties are likely to change within a landfill and the waste is likely to decompose with time. An alternate method for estimating landfill geotechnical properties is using in-situ testing devices that provide accuracy with minimal efforts and costs. In the field of geotechnical engineering, a device that meets these criteria for soil testing is the Cone Penetrometer. The unit weight, moisture content, friction angle and cohesion influence the stability of landfill side slopes and interfaces among landfill components. True cohesion between particles is unlikely in landfills but there may be significant cohesion that results from interlocking and overlapping of the landfilled constituents (Singh and Murphy [3]).

This paper aims to evaluate the performance of slopes in landfills that may allow the co-disposal of sludges and biosolids, using standard slope stability analyses. Field tests using a Cone Penetrometer are carried out, followed by a slope stability analysis on landfill models using the computer software SLOPE/W (Geo-Slope [4]).

\section{Field site description}

The field study was conducted at the Highlands County Landfill, located in Highlands County, Sebring, Florida. Two test MSW pads, namely Pilot Area (PA) and Control Area (CA) were constructed at this location. Each test pad was about 120 by 100 feet in plan dimensions at it base and 40 by 60 feet at the top. The height of each test pad was about 10 feet. The compacted waste below the test pads had an average thickness of about 13.2 feet. Liquid biosolids from the City of Sebring Wastewater Treatment Plant were added to the waste in the PA. Two tanker loads of unstabilized biosolids in the form of sludge were transported from the City of Sebring Wastewater Treatment Plant to the site. The liquid sludge had a solids content of $23 \mathrm{~g} / 1$ or about $3 \%$. The sludge volume was about 1,202 cubic feet which occupied about six inches of depth on an average. The measured decrease in the surface elevation of the impounded sludge due to infiltration of sludge moisture into the underlying and surrounding MSW over 48 
hours was about 0.8 inches on an average. Based on the rate of evaporation for the site area for the month of May, approximately 0.45 inches of the measured decrease in sludge level over 48 hours could be attributed to evaporation losses from the surface. The resulting average thickness of the remaining sludge in the entire impoundment was about 4.75 inches.

The bulldozer operator had no problem operating the machine over the top of the sludge. The bearing capacity for the wide track, low ground pressure bulldozer (36-inch wide tracks) was excellent with no machine tilting or soft spots were encountered. The three-foot thick layer of MSW was compacted into a layer about 1.5 feet thick, without any observed extrusion of sludge to the surface. No soft spots were encountered and no pumping action was observed as the compactor moved back and forth. Additional MSW was then placed, spread, and compacted on the pad. All four side slopes were constructed at a final grade of about 1:3. The entire surface of the test pad was covered with 24 inches of loosely spread intermediate cover soil. The Control Area (CA) was prepared in a similar manner without the addition of sludge.

A total of 28 cone penetration tests were then conducted at these areas, five at $\mathrm{CA}$ and twenty three at PA. CPT locations were taken as close to edge of the slope as the truck could be placed.

\section{Methodology}

\subsection{Cone penetration tests}

The CPT utilizes electrical transducers rather than analog gauges to obtain a nearly continuous profile of point (tip) resistance, sleeve friction and pore pressure with depth. Specialized data acquisition hardware and software was used to record readings from the transducers at a frequency of approximately five readings per second. Electrical signals reading were then converted to engineering units of stress using device-specific calibration factors. Immediately after the sounding was completed, the borehole was filled with bentonite clay to the top of the intermediate soil cover to prevent water and gas transport from the landfill.

The desired depth of soundings in pilot area and control area was about 20 feet from the intermediate soil cover. Ten soundings had to be terminated at depths shallower than the intended depth due to buried obstructions encountered in the path of the cone in the test areas. The data was stored and used in a subsequent statistical data reduction analysis to determine the geotechnical properties for use in subsequent slope stability modeling. A frequency distribution curve of the values of tip resistance was created for each sounding. In order to eliminate outliers in the tip resistance values, the cut off frequency values was selected as 20 . Unrealistic tip resistance and pore pressure values are possibly due to the heterogeneous material and obstructions.

Based on the field results for tip resistance and sleeve friction, an attempt was made to estimate the location and potential effect of the biosolids layers within the MSW mass. However, this layer could not be identified explicitly, as the 
biosolids added had only about 3\% solids content; it is likely that the wet material got very well mixed with the MSW.

The CPT data provides a repeatable index of the aggregate behavior of the in situ soil in the immediate area of the probe (Robertson [5]). Based on the average values of the MSW parameters, the landfill material is seen to behave similar to "Coarse Grained Sandy-Silty Soil". Since the material is classified as sand, charts proposed by Robertson and Campanella [6] may be used to estimate the friction angle for the MSW. The resulting friction angle values were adjusted proportionally for variation in density. This is a conservative approach and the actual friction angle $(\phi)$ may be somewhat higher. From the generalized equation for friction angle, the average value of friction angle was found to be $29^{\circ}$.

\subsection{Slope stability analysis}

The behavior of MSW is assumed to be frictional in nature and is governed by the Mohr-Coulomb criteria. The slope stability analysis was conducted using the software SLOPE/W. Daily or intermediate cover was not taken into account in the slope stability analysis. The biosolids or sludges were placed in trenches. The geotechnical properties needed for modeling the slope stability were determined in the field using CPT testing as discussed in the previous section. The landfills were analyzed under circular failure and block failure conditions, and the factors of safety against these modes of failure were evaluated. This paper only presents the results of the study with circular failure. A factor of safety is an index indicating the relative stability of a slope. It does not imply the actual risk level of the slope due the variability of input parameters. With probabilistic analysis, two useful indices are available to quantify the stability or the risk level of a slope. These two indices are known as the probability of failure and the reliability index. The input parameters required for the MohrCoulomb Failure Model are unit weight, angle of internal friction and cohesion with associated standard deviation (SD) values for each parameter.

Table 1 shows the properties of each material used as input in the model. In Table 1, MSW+BS1, MSW+BS2 and MSW+BS3 refer to layers of different moisture content, which indicate the gradual migration of the biosolids' moisture into the MSW. This is reflected in the gradation of shear strength parameters with addition of biosolids to the MSW. The shear strength parameters were estimated from the field data obtained using the CPT.

For landfills modeled using the circular failure model, the radius of failure plane and the center of the circular failure plane are required to be defined. The radius of the failure plane was specified such that it covers a large range of radii, while the grid for the center of the circular failure plane was chosen so that the minimum factor of safety lies within the grid. Once the landfill model is developed and the grid and radii for the failure plane are specified, slope stability analysis is carried out. A typical result from the program is shown in Figure 1 indicating the failure plane and the minimum factor of safety for the chosen grid. 
Table 1: $\quad$ Landfill material properties used in modelling.

\begin{tabular}{|l|l|l|l|l|}
\hline $\begin{array}{l}\text { Material } \\
\text { Description }\end{array}$ & $\begin{array}{l}\text { Unit Weight } \\
(\mathrm{pcf})\end{array}$ & $\begin{array}{l}\text { Cohesion } \\
(\mathrm{psf})\end{array}$ & $\begin{array}{l}\text { Friction Angle } \\
(\text { degrees })\end{array}$ & Source \\
\hline MSW & $70(\mathrm{SD}=5)$ & 0 & $29(\mathrm{SD}=5)$ & Field CPT \\
\hline $\mathrm{BS}$ & $35(\mathrm{SD}=5)$ & 0 & 0 & Ref [7] \\
\hline $\mathrm{MSW}+\mathrm{BS} 1$ & $70(\mathrm{SD}=5)$ & 0 & $7(\mathrm{SD}=5)$ & $\begin{array}{l}\text { Extrapolated } \\
\text { Results }\end{array}$ \\
\hline MSW $+\mathrm{BS} 2$ & $70(\mathrm{SD}=5)$ & 0 & $15(\mathrm{SD}=5)$ & $\begin{array}{l}\text { Extrapolated } \\
\text { Results }\end{array}$ \\
\hline MSW $+\mathrm{BS} 3$ & $70(\mathrm{SD}=5)$ & 0 & $22(\mathrm{SD}=5)$ & $\begin{array}{l}\text { Extrapolated } \\
\text { Results }\end{array}$ \\
\hline Sand Liner & $30(\mathrm{SD}=3)$ & 0 & $40(\mathrm{SD}=5$ & Ref [8] \\
\hline
\end{tabular}

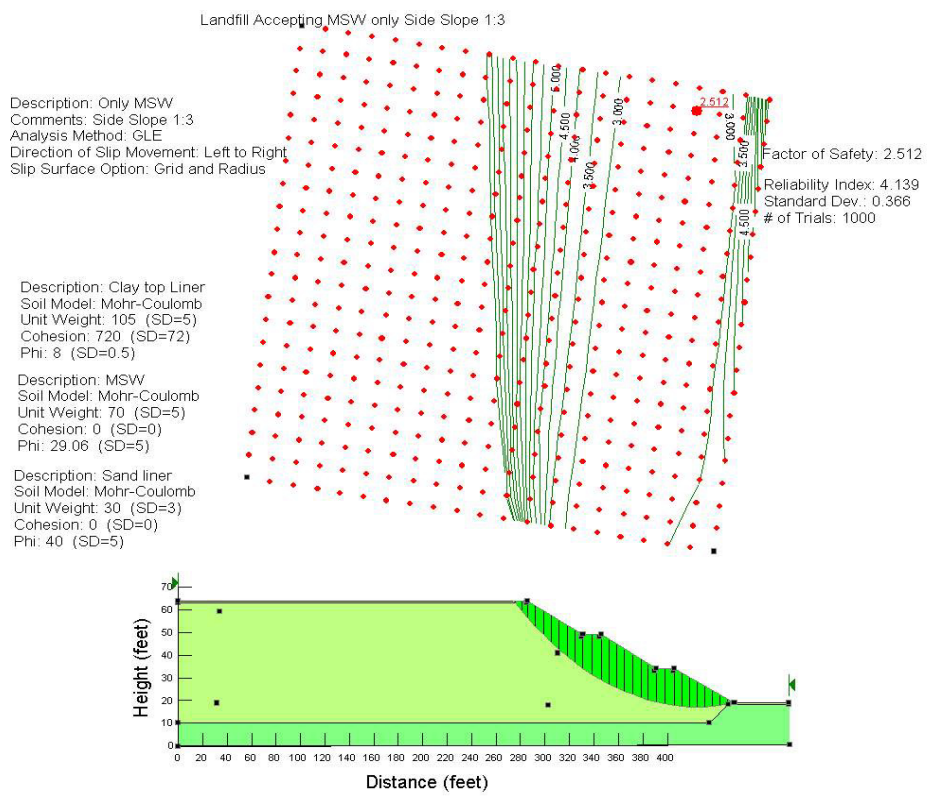

Figure 1: Typical slope stability analysis - landfill of slope 1:3 with MSW only - circular failure.

Next, a landfill model was generated incorporating the placement of biosolids in trenches as shown in Figure 2. The width of the trench was about 2-2.5 feet and spacing between the trenches was about fifteen feet. The depth of the trenches was about six feet. Biosolids were added in the trenches. The trenches were then filled with regular MSW and compacted with regular effort. The compaction effort needed to compact the waste layer was reduced based on 
discussions with the landfill operators. Slope stability analysis was then conducted on landfill models with side slope varying from 1:2 to 1:4. Although side slope 1:2 is not permitted in Florida state regulation, it is studied as an extreme condition.

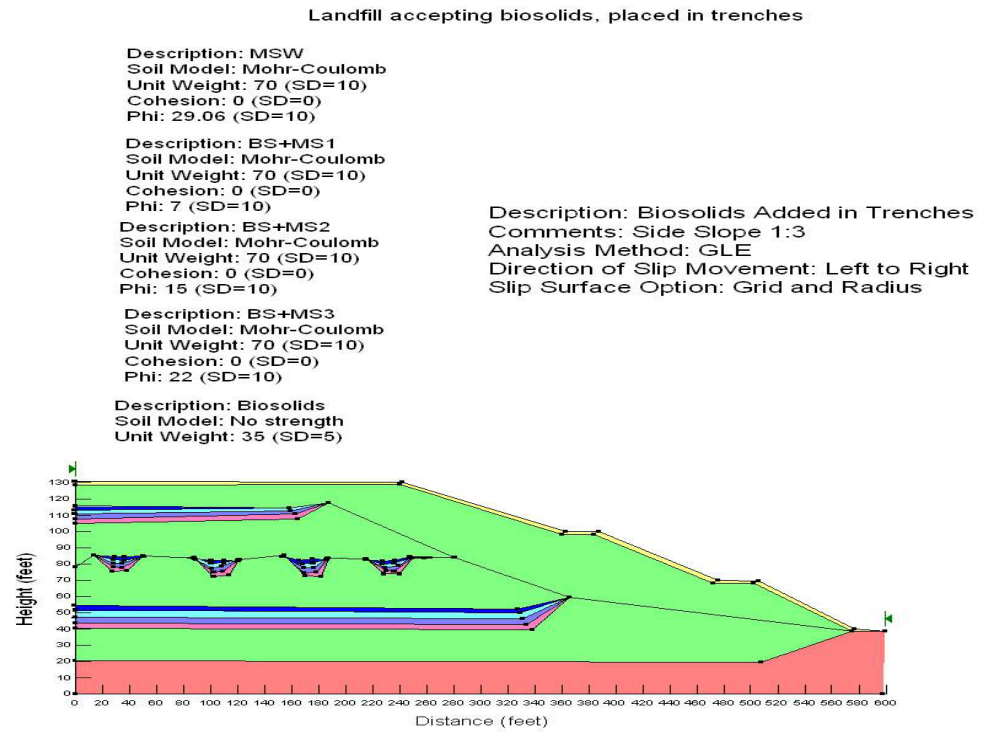

Figure 2: $\quad$ Typical landfill profile with biosolids placed in trenches.

\section{Results}

The results are reported in two parts - results from the field tests and those from the subsequent slope stability study. Field tests conducted consisted of Cone Penetration Test on areas receiving biosolids, areas without biosolids. The average tip resistances range from 60 to 100 tsf, the average sleeve resistance is in the range of 0.7 to 2.4 tsf. These are similar to the range of tip resistance and sleeve resistance values from previous literature on CPT used in landfills. The region of solid waste is characterized by a highly variable set of test results.

The CPT results indicated that the cone frequently encountered stiff objects, which produced sharp peaks in the tip resistance measurements resulting in highly variable readings. However, a trend of increasing lower bound tip resistance with depth, was apparent in most the tests. It is important, therefore, to reduce these data by eliminating unrealistic outliers based on cone tip resistance and pore pressure values. From the CPT probes, daily or interim cover soil could not be distinguished from the refuse.

Using the method proposed by Robertson and Campanella [6], it is possible to derive the profile of friction angle as a function of depth from the piezocone penetration data for the landfill. The average value of friction angle is $29^{\circ}$. This value of friction angle $(\phi)$ is used for slope stability analyses. 
Slope stability analysis was conducted using commercially available software SLOPE/W on models of landfills with and without biosolids. Biosolids were placed in trenches and different values of side slope such as 1:2, 1:3 and 1:4 were modeled. Three scenarios are considered.

1. Landfill with MSW only.

2. Landfill with MSW and biosolids which were placed in trenches.

3. Landfill with MSW and biosolids in trenches taken close to the edge of the slopes.

Table 2 presents the results of the factor of safety (FOS) of landfill slopes for the different conditions that are modeled for the circular failure mode.

Table 2: $\quad$ Factor of safety for landfills with different side slopes.

\begin{tabular}{|c|c|c|c|c|c|c|}
\hline $\begin{array}{c}\text { Side } \\
\text { Slope }\end{array}$ & \multicolumn{2}{|c|}{ MSW only } & \multicolumn{2}{c|}{ MSW and Biosolids } & \multicolumn{2}{c|}{$\begin{array}{c}\text { MSW and } \\
\text { Biosolids with } \\
\text { trenches close to } \\
\text { side slope }\end{array}$} \\
\hline & FOS & $\begin{array}{c}\text { Reliability } \\
\text { Index }\end{array}$ & FOS & $\begin{array}{c}\text { Reliability } \\
\text { Index }\end{array}$ & FOS & $\begin{array}{c}\text { Reliability } \\
\text { Index }\end{array}$ \\
\hline $1: 2$ & 1.94 & 16.3 & 1.72 & 19.0 & 1.26 & 7.0 \\
\hline $1: 3$ & 2.51 & 19.3 & 2.17 & 17.4 & 1.28 & 6.4 \\
\hline $1: 4$ & 2.96 & 21.8 & 2.31 & 3.4 & 1.75 & 11.1 \\
\hline
\end{tabular}

\section{Discussion}

Flattening the slope not only reduces the sum of the driving forces, but also tends to force the failure surface deeper into the ground. The change in length of the failure surface increases in the resisting forces because the shear strength is distributed over a wider area, thereby enhancing stability. Results for FOS suggest that the stability of the landfill slope has been reduced with the addition of biosolids.

The factor of safety is clearly reduced if the biosolids trenches are placed close to the edges of the slopes. This scenario allows a weak plane to develop close to the side slope and encourages the failure plane to pass through this weak layer. This situation is considered unstable and needs to be avoided in the field. These results are similar to the previous work by Koodhathinkal [7] who tested MSW with biosolids in a laboratory study. The lower values may be attributed to a lower friction angle for biosolids that are placed as discrete layers and may not be completely mixed in with the MSW.

Disposing of biosolids in trenches is a feasible solution from both slope stability point of consideration and ease of field application practice. However, trenches should not be close to the edge side of the landfill as the factor of safety reduces significantly.

Berms at the toe of slopes contribute to resisting forces and as a result there is an increase in the factor of safety when considering local failures. 


\section{Conclusions}

Based on the field explorations, the angle of internal friction was found to be about $29^{\circ}$. The most suitable approach to introducing biosolids into the landfill was in the form of trenches. From the slope stability analysis, it was found that the factor of safety reduces significantly with the introduction of biosolids due to a reduction in the shear strength and with increase in the overall moisture content.

\section{References}

[1] Sharma, H. D., Dukes, M.T. and Olsen, D.M. (1990). "Field Measurement of Dynamic Moduli and Poisson's Ratios of Refuse and Underlying Soils at a Landfill Site." Geotechnics of Waste Fills - Theory and Practice ASTM STP 1070.

[2] Sadek, S., Abou-Ibrahim, A., Manasseh, C. and El-Fadel, M. (2001). "Stability of Solid Waste Sea Fills: Shear Strength Determination and Sensitivity Analysis." International Journal of Environmental Studies 58: 217-234.

[3] Singh, S., and Murphy Bruce (1990). "Evaluation of the Stability of Sanitary Landfills." Geotechnics of Waste Fills - Theory and Practice.

[4] Geo-Slope (2001). SLOPE/W for Slope Stability Analysis Version 5, GeoSlope.

[5] Robertson, P. K. (1990). "Soil classification using the Cone Penetration Test." Canadian Geotechnical Journal (27): 151-158.

[6] Robertson, P.K. and Campanella, R.G. (1983). "Interpretation of Cone Penetration Tests, Part I: Sands," Canadian Geotechnical Journal, Ottawa, Vol. 20, No. 4, pp. 718-733.

[7] Koodhathinkal, B. R. (2003). Stability of Slopes in a Class I Landfills with Co-Disposal of Sludges and Biosolids. MS Thesis, University Of Central Florida.

[8] Das, B. M. (2000). Principles of Geotechnical Engineering, Brooks/Cole Publishers. 